\title{
Legal Agreements and the Capacities of Agents
}

(Published in Enrique Villanueva, ed., Law and Philosophy of Action (Leiden: Brill, 2014))

Andrei A. Buckareff

Marist College
Lara E. Kasper-Buckareff

Legal Services of the Hudson Valley

\section{Introduction}

Most work at the intersection of law and the philosophy of action focuses on criminal responsibility. Unfortunately, this focus has been at the expense of reflecting on how the philosophy of action might help illuminate our understanding of issues in civil law. In this essay, focusing on Anglo-American jurisprudence, we examine the conditions under which a party to a legal agreement is deemed to have the capacity required to be bound by that agreement. We refer to this condition as the capacity condition.

We begin by showing how recent work on the metaphysics of powers might ground an account of the role of capacities in the metaphysics of intentional agency. After discussing the capacity to contract in Anglo-American jurisprudence, we show how the general ontology of capacities and agency sketched can ground and help clarify legal thinking about capacity. We argue that when we couple our understanding of capacity with relevant recent data from developmental neuropsychology, a lacuna in Anglo-American contract law becomes evident. Specifically, it appears that persons in early adulthood do not clearly satisfy the conditions requisite for them to satisfy the capacity condition. In the light of this, we sketch some potential solutions that are compatible with existing legal standards 
and would contribute to a more consistent application of the capacity condition in contract law.

2. Capacities and the metaphysics of agency

In this section, we will first provide a brief overview of the basic ontological framework for our theorizing about the metaphysics of agency. Building on this framework, we then sketch an account of how to think about the capacities of agents and the role they play in ordinary exercises of agency such as we find with our dayto-day array of mental and overt actions.

\subsection{Objects, powers, and capacities}

The starting point for thinking about the capacities of agents is with agents themselves. We here assume a two-category ontology on which the basic ontological categories are objects/substances and properties. We will have less to say about objects and more to say about properties in what follows.

We assume that human agents are objects or substances. We assume that they are not simple substances. Rather, they are complex substances. That is, they have substantial parts. As complex substances, they can be truthfully described as systems whose parts are organized in such a way that they can interact with other systems and larger systems of which they are constituents in ways that are characteristic of intentional agency. As for the nature of simple substances and what objects in the universe count as simple substances, we shall remain silent in the remainder of this paper. 
What matters for our purposes is that agents qua objects can be truthfully described as possessing properties. ${ }^{1}$ We will characterize the framework for thinking about the metaphysics of agency in terms of how at least some of these properties interact with one another.

Regarding properties, we will assume that there are real properties. Moreover, we will assume that the most viable alternatives take properties to be immanent universals or they take properties to be tropes. ${ }^{2}$ What is important for our purposes is that properties be understood as ways that individual objects are

\footnotetext{
${ }^{1}$ We prefer the terms 'possess' and 'has/have' over 'instantiates' and 'exemplify'. The latter terms imply a view of properties as immanent universals. An object can possess a property whether or not properties are particulars (tropes) or universals. Another advantage of this terminology is that it allows us to distinguish between those properties an object possesses but are not manifested at a moment and those properties that are possessed and manifested. For instance, sodium chloride possesses the dispositional property of being dissolvable in water. It only manifests this property, however, when it comes into contact with water-i.e., when the dissolvability of the salt is paired with the water's disposition to dissolve salt (for a defense, see Molnar 2003, chapter 4).

2 For a defense of properties as immanent/in rebus universals, see Armstrong 1978, 1989, and 1997. Representative trope-theoretic accounts are offered in Campbell 1981 and 1990, Heil 2003 and 2012, Martin 2008, Molnar 2003, and Williams 1953. There are important differences between Campbell and Williams, on the one hand, and Heil, Martin, and Molnar, on the other. Specifically, Campbell and Williams assume a one-category ontology with objects being bundles of tropes. Heil, Martin, and Molnar include irreducible objects in their ontologies, with tropes as modes or ways objects are. Given the two-category ontology being assumed in this paper, if some version of trope-theory were to be assumed, it would be closer to the views endorsed by Heil, Martin, and Molnar.
} 
(they are modes of objects). Objects, then, are in a sense ontologically basic since there are no properties without the objects that have them.

Most importantly for our purposes in this paper, we assume that at least some properties are dispositional properties, endowing objects with causal powers. ${ }^{3}$ Any change in an object's dispositional properties results in a change in its causal powers (Heil 2003, 115). In fact, the dispositional properties of an object just are the causal powers of the object. So gaining or losing dispositional properties results in a net gain or net loss of an object's causal powers. If this is true of objects generally, then it is true of agents.

Regarding the manifestation of dispositional properties, individual causal powers are generally multi-track and directed at "endless manifestations with an infinity of present or absent, actual or nonactual alternative disposition partners" (Martin 2007, 29). C.B. Martin suggests thinking of the projectivity of an individual disposition as constituting a complex web, which he calls a "Power Net" $(2007,29)$. Consider the sphericity of a ball. ${ }^{4}$ This property of the ball is capable of diverse manifestations depending upon the property with which it comes into contact that

\footnotetext{
${ }^{3}$ Echoing Alexander's Dictum/the Eleatic Principle, we would contend that all real properties are dispositional. Moreover, all properties are qualitative/categorical. They have, to use C.B. Martin's language, "a dual nature": "in virtue of possessing a property, an object possesses both a particular dispositionality and a particular qualitative character" $(2007,44)$. John Heil also defends this view, dubbing it "the identity theory" of properties (see Heil 2003, chapter 11). On this point (and others), Molnar (2003) parts company with Heil and Martin. For additional defenses of versions of the identity theory, see Engelhard 2010, Ingthorsson 2013, Jacobs 2011, Mumford 1998, Strawson 2008 ${ }^{4}$ The following example is borrowed from Heil 2012, 121.
} 
serves as a disposition partner. The ball will roll if it comes into contact with a solid surface. It will leave a concave, reversible impression if it comes into contact with a surface with the appropriate elasticity. And so on. The same disposition is manifested in different ways with different partners.

We assume that the manifestation of a dispositional property should not be confused with the effect of its manifestation. ${ }^{5} \mathrm{~A}$ framework for understanding how the manifestation of a causal power figures in the bringing about of an effect is provided by the dispositionalist theories of causation (DTC) proposed by John Heil (2012) and C.B. Martin (2007). ${ }^{6}$

The standard story of causation takes causation to be a diachronic relation between two events. ${ }^{7}$ On the version of DTC assumed here, causation can be either diachronic or synchronic and involves a causing and an outcome of the causing. The causing is symmetrical and involves the mutual manifestation of dispositional properties that are manifestation partners. When the proper manifestation partners of an object or more than one object are paired, the powers of the object(s) are manifested and, as a result of the pairing, an outcome is produced which is the possession of some further property/properties by an object. For every causing, there is an outcome, which is the effect of the causing (the causing being the cause).

\footnotetext{
5 See Molnar 2003, 194-198.

6 There are some slight differences between the two. However, their views are very close. Heil's position has the advantage of being more clearly articulated. The view we articulate here is heavily indebted to Heil's work. But there are some possible slight differences.

7 See Davidson 1980 for a presentation of the standard story of causation.
} 
While the causing is symmetrical, the production of the outcome is asymmetrical. But the process that consists of the causing and the production of the outcome can be either simultaneous or occur at different times.

Consider a relatively simple case of the sort of causal process we have in mind that is commonly discussed in the literature. Assume that sodium chloride has the dispositional property of being soluble and that $\mathrm{H}_{2} \mathrm{O}$ has the dispositional property of dissolving sodium chloride. When these properties are paired when some salt comes into contact with water they mutually manifest their relevant dispositions. The outcome of the causing that occurs when the properties are paired is a liquid with the properties characteristic of brine (if the sodium chloride is sterile, we get saline).

The ontological picture sketched thus far may be regarded as unobjectionable, but one may worry whether we have anything to say about capacities. We here assume that capacities just are dispositional properties (see Martin 2008, 84-85). More specifically, they are relatively non-specific, complex dispositional properties of objects that are composed of more basic powers of an object. Differently stated, an object has a capacity in virtue of certain powers it possesses. So, for instance, a human agent has the capacity for responding to practical reasons if the agent has a suitable range of powers that enable her to acquire intentions and perform actions as a consequence of encountering reasons that favor a particular action or outcome that requires a particular action. We will say more about this in a moment. For now, simply notice how general the relevant capacity is. Contrast this with an agent's desire to satisfy her hunger. The property 
possessed by the agent who so desires is more specific and less complex (although it is still a complex property).

\subsection{Putting the ontology to work}

Normal adult humans can be truthfully described as paradigmatic rational agents. The appellation "rational agent" when used of human agents and any other possible agents with powers like human agents is somewhat misleading, if not tendentious.

What we do not mean when we refer to humans as "rational agents" is that they always do what is rational. Human agents often fail to do that which is most reasonable. In fact, there is plenty of evidence that supports the claim that humans are quite irrational (Dawes 2002). Moreover, we do not mean to suggest that only rational agents act for reasons. If we distinguish between normative and motivating reasons for action, ${ }^{8}$ then surely a non-rational agent can act for motivating reasons that can be offered to explain why the agent acts as it does. We simply assume that motivating reasons for action are the content-bearing mental states of agents that we invoke in providing psychological explanations of their behavior. Normative reasons for action may include a wide range of considerations that favor a course of action and an agent's actions are rational or irrational in the light of their acting on such reasons.

While we admit a distinction between motivational and normative reasons, this is not to suggest that only actions performed for normative reasons can be assessed for rationality. There is an important sense in which, in the light of either a rational or a non-rational agent's motivational reasons for action, a course of action

\footnotetext{
${ }^{8}$ For a defense of this distinction, see Mele 2003, especially chapter 3.
} 
can be objectively interpreted as instrumentally rational. So if Fred the cat wants food because he is hungry and believes that meowing will get the attention of his human companions, his meowing that is motivated by his want and belief is rational given his goal of getting fed.

While both rational agents and non-rational agents may do things that are more or less instrumentally rational given their motivational reasons, rational agents possess a more developed capacity to respond to normative reasons than non-rational agents. In particular, they can appreciate and conform their actions to a more varied array of considerations that are represented in their conscious beliefs as favoring or counting against acting or omitting to act in a particular way. ${ }^{9}$ These considerations we take to be normative reasons. Such normative reasons include, but are not limited to, facts about the world, the dictates of morality and social convention, and the requirements of the law. It is the possession of this capacity that allows rational agents to be justifiably held morally and legally responsible for their actions and omissions. ${ }^{10}$

\footnotetext{
${ }^{9}$ Whether normative reasons must objectively favor a particular course of action over others (see Dancy 2000) or whether they are what an ideally rational agent would desire to conform his or her actions to (see Smith 1994) is a debate on which we do not wish to take a stand in this essay. For our purposes, that a normative reason is taken to be what an agent believes is required in some situation (whether the requirement is legal, moral, or prudential) is sufficient for our purposes.

${ }^{10}$ While our concern is not with free agency, our account belongs in the same family as theories of free agency that emphasize that an agent must have a capacity or mechanism that is appropriately reasons-responsive. Examples of such theories are Fischer 1995, Fischer and Ravizza 1998, Nelkin 2011, and Wolf 1993.
} 
Consider the following example. Suppose that Lydia and Katrina are normal adult human agents. Fred the cat is, of course, a cat. We are assuming that in virtue of being normal adults, Lydia and Katrina are rational agents. Fred is a non-rational agent in the sense of not possessing the same sort of developed capacity to respond to normative reasons possessed by Lydia and Katrina.

Suppose that Fred is hungry. In an effort to get Lydia's attention (meowing did not work), he jumps onto the shelf of a large bookcase in Lydia's living room and pushes a Matryoshka doll made by her grandmother from the shelf, knocking it on to the floor. Now suppose that Katrina is hungry. She knocks the same Matryoshka doll made by Lydia's grandmother from the same location on the shelf on to the floor. There are differences between Fred and Katrina as agents and how their actions are evaluated.

But Fred and Katrina are also similar. Fred wants to be fed and must get Lydia's attention. He believes that he will get her attention by knocking an object from the shelf (and the Matryoshka doll is the easiest thing for him to knock down). ${ }^{11}$ Katrina believes something similar. But, while Lydia is upset with Fred, she does not have the same emotional response to Fred's action that she has when Katrina does the same thing. ${ }^{12}$

\footnotetext{
11 We assume the representational content of Fred's mental states involve pictorial imagery, not verbal imagery.

${ }^{12}$ Such emotional responses are called "reactive attitudes" in the literature on moral psychology. The locus classicus for discussion of reactive attitudes is Strawson 1962.
} 
It would be inappropriate to hold Fred accountable for what he does in the same way one might hold Katrina accountable for what she does. Simply put, part of what explains the difference is that Katrina has a capacity that Fred lacks. The relevant capacity that Katrina possesses that Fred does not (or at least not to the same extent as Katrina) is the capacity to be responsive to a wider range of types of reasons. In particular, Katrina can appreciate that the standard rules of etiquette would proscribe knocking items off of shelves. Moreover, she would understand the value of the Matryoshka doll for Lydia and it is reasonable to expect her to respect Lydia's personal property. Fred has no such understanding of the impropriety of his behavior. He merely wants to get Lydia's attention and recognizes that by pushing an item off the shelf, he can get it.

Of course, there will be times when we are considering the actions of agents like Katrina and only be concerned with what motivated them to act as they did and how their motivating reasons (and any other reasons) figure in an explanation of what they did. In such cases, there is no practical difference between agents like Katrina and agents like Fred the cat. Of course, Katrina's representational powers are greater than Fred's. Thus, her mental life will be richer than Fred's. An explanation of why she does something and the sorts of reasons we may offer in such an explanation will be more varied than what we get with Fred. But the difference is often just a difference of degree and complexity and not a difference of kind. It is only when we shift from explaining to evaluating that a difference of kind emerges. And the relevant difference is that agents like Katrina and other normal adult humans can and do act for a wider range of reasons that they take to commend 
some actions and count against others. Sometimes these reasons may even conflict (such as when social pressures and moral commitments clash). And these reasons are among the causes of intentional actions of agents such as Katrina's, and Katrina guides her actions in the light of such reasons. In an agent like Fred, while his thoughts may motivate, cause, and explain his actions, the sort of conflict between reasons such as Katrina may experience does not exist, or if it does, it does so to a far lesser extent than in an agent such as Katrina.

A rational agent's capacity to respond to reasons for action would have the complexity we suggested above is characteristic of capacities. An aspect of its complexity would be its relative non-specificity with respect to the range of manifestations toward which it is directed. Broadly, the relevant rational capacity with which we are concerned here would be directed at conforming to what is prescribed by reasons for action-including normative reasons-in coming to have an intention and in exercising intentional agency. Any specificity with respect to what the agent actually does or omits to do would be determined by the manifestation partners of the capacity. These would include both a wide range of different dispositional properties that are constitutive of normative reasons for action and also the dispositional properties constitutive of motivating reasons for action. Importantly, the relevant capacity would also be partnering with other capacities of the agent. ${ }^{13}$

\footnotetext{
${ }^{13}$ Keep in mind that the process of acquiring an intention and of an intention causing an action on the account assumed here can be one where causation is synchronic. Hence, the cause (the causing) and the effect (the outcome) can be contemporary. This approach provides resources for proponents of
} 
For example, consider Lydia's belief that a particular action $A$ is in violation of a contract and her desire to avoid being penalized for acting contrary to the terms of the contract. Her desire disposes her to avoid actions that could result in her being penalized for acting contrary to the terms set forth in the relevant contract. Her belief disposes her to identify tokens of the relevant action-type that fall under what is proscribed by the contract. Her belief and desire partner with her capacity to respond to reasons with the acquisition of a present-directed intention as the outcome. Assuming Lydia has an intention to omit $A$-ing by doing something else, her intention disposes her to refrain from $A$-ing by doing something else. In this case, her capacity to respond to reasons partners with the dispositional properties of the outputs of her perceptual and/or proprioceptive experiences along with her intention. The outcome of the manifestation of these different powers that are partnered is a particular action that allows her to avoid $A$-ing. If she has an intention to omit $A$-ing where the omission is basic, then she is disposed to avoid $A$-ing and respond as required to any perceptual or proprioceptive feedback in order to avoid $A$-ing.

With this basic framework in place, we can now move to consider the role capacities play in contract law in Anglo-American jurisprudence followed by

the causal theory of action (CTA) to address some standard objections to the CTA on which an agent spontaneously acts without there being any rationalizing mental cause that temporally preceded the action. An example of this sort of objection in the action theoretic literature is found in Frankfurt 1978. For a similar sort of strategy against the CTA from the philosophy of law, see Simester 1996. For a recent collection with state of the art essays on the CTA, see Aguilar and Buckareff 2010. 
considering how the framework we have provided may help us think about the capacity to contract. Finally, we will consider the problem posed by cases where the capacity of an agent is questionable owing to age, and we will sketch some different candidate solutions.

\section{The Capacity to Contract in Anglo-American Jurisprudence}

According to the standard account of a contract in Anglo-American jurisprudence, "A contract is a promise or a set of promises for the breach of which the law gives a remedy, or the performance of which the law in some way recognizes as a duty" (Braucher and Farnsworth 1981, Section 1) ${ }^{14}$ An agent's capacity to contract is of importance because an agent who lacks legal capacity is not contractually bound. An agent possesses the capacity to contract if she "manifests assent to a transaction ... unless [s] he is (a) under guardianship, or (b) an infant, or (c) mentally ill or defective, or (d) intoxicated" (Ibid., Section 12). We will focus on the status of minors and infants along with those with mental disabilities in this section. How the law handles both groups is relevant for what follows in the next section when we shift our attention to young adults.

In common law countries minors or infants lack the capacity to contract, so their contracts are voidable, i.e., minors can disaffirm their contracts and avoid their legal duties thereunder (Ibid., Section 7). ${ }^{15}$ Contrast the other party to an agreement

\footnotetext{
${ }^{14}$ For further clarification on the status of contracts as promises and the normative implications, see Pratt 2007.

${ }^{15} \mathrm{~A}$ contract that is void is void $a b$ initio and its terms are unenforceable. An example is a contract with illegal terms, such as a contract to buy illegal drugs.
} 
with a minor who is still legally bound to perform her contractual duties, assuming the other party has legal capacity.

Most jurisdictions within the Anglo-American tradition define a minor or infant as "a person who has not attained the age of eighteen years" (NY General Obligations Law 2013, Section 1-202). ${ }^{16}$ Some Anglo-American jurisdictions designate the age of nineteen as the end of minority status (Braucher and Farnsworth 1981, Section 14). Very few common law jurisdictions have retained the common law rule that provides that twenty-one is the age of majority. ${ }^{17}$ It has been suggested that, at least in the United States, "[t]he impetus for lowering the age of majority probably came from the widespread draft of those under twenty-one and from the lowering of the voting age to eighteen" (Ibid.).

Generally stated, persons who contract as minors may raise the affirmative defense of infancy when sued for breach of contract and disaffirm the contract (Ibid., Section 14$).{ }^{18}$ For this reason, minors' contracts are said to be voidable (Ibid.). On the other hand, persons who contract as minors may ratify or affirm such contracts by failing to disaffirm within a reasonable period of time after reaching the age of

16 See Braucher and Farnsworth 1981, Section 14 (which compiles the statutes for all 50 states in the U.S.A.). See also, the New South Wales, Australia's Minors (Property and Contracts) Act of 1970, Section 8, and, in the United Kingdom, the Family Law Reform Act 1969, Part I.

17 In the U.S.A., the only state to retain this common law rule is Mississippi.

18 An exception under quasi-contract theory is agreements to procure necessaries, such as food, clothing, shelter, and medical care. See Braucher and Farnsworth 1981, Section 12. Other exceptions are statutory creatures that exist in some jurisdictions, such as those pertaining to educational loans and insurance contracts. 
majority, or by taking actions after reaching the age of majority that are deemed ratification. ${ }^{19}$

With respect to the right to disaffirm, the courts have found that, Th[e] right [to disaffirm] is founded in the legal concept that an infant is incapable of contracting because he does not understand the scope of his rights and he cannot appreciate the consequences and ramifications of his decisions. Furthermore, it is feared that as an infant he may well be under the complete influence of an adult or may be unable to act in any manner which would allow him to defend his rights and interests. (Shields v. Gross, 58 N.Y.2d 338, 348-349, Court of Appeals of New York, 1983)

Upon disaffirmance, the title to any property received by the minor under the contract revests in the other party. "If the consideration received by the infant has been dissipated by him, the other party is without remedy unless the infant ratifies the contract after coming of age or is under some non-contractual obligation" (Braucher and Farnsworth 1981, Section 14).

A non-contractual obligation may be found in quasi-contract or implied-inlaw contract theory under which persons who disaffirm contracts made as minors and under which they have received benefits are generally liable for restitution

\footnotetext{
${ }^{19}$ See, e.g., Horowitz v. Manufacturers' Trust Co., 239 A.D. 693 (Supreme Court of New York, Appellate Division, First Department, 1934) and Jones v. Dressel, 623 P.2d 370 (Supreme Court of Colorado,
} 1981). 
(Ibid., Section 62). ${ }^{20}$ But, that restitution "is limited to returning what he still has of what he received or the proceeds" (Ibid., Section 62 and Section 139).

While the person who enters into a contract as a minor generally need only raise and prove her minority status as a defense to avoid her contractual duties, the person with a mental disability who seeks to avoid his contractual obligations must raise and prove as a defense one of the following, that "by reason of mental illness or defect ... he is unable to understand in a reasonable manner the nature and consequences of the transaction, or he is unable to act in a reasonable manner in relation to the transaction and the other party has reason to know of his condition" (Ibid., Section 15). ${ }^{21}$ With respect to the first prong of the incompetency defense, the person's understanding of the transaction may be partial or non-existent. Where partial, "the controlling consideration is whether the transaction in its result is one which a reasonably competent person might have made" (Ibid., Section 15). With respect to the second prong, the person understands the transaction, but, for instance, due to his mental disability he is unable to appreciate facts that are

\footnotetext{
20 "An implied-in-law contract is not actually a contract, but instead a remedy that allows the plaintiff to recover a benefit conferred on the side of the defendant" (Garner 1999, 322).

${ }^{21}$ In the Mental Capacity Act 2005, England and Wales have adopted an incompetency defense that is somewhat of a hybrid of the two-pronged Restatement standard. Also, of importance, in common law jurisdictions, persons with mental disabilities for whom guardians have been appointed are unable to incur contractual duties. See, e.g., Braucher and Farnsworth 1981, Section 13.
} 
relevant to the transaction that weigh against entering into the transaction, and the other party to the contract knows of his condition. ${ }^{22}$

As noted above, what the law assumes is that once a person has reached the age of majority, the agent possesses the capacity to contract. It is this assumption of Anglo-American jurisprudence that we will question in the next section.

\section{Capacity to Contract, Neurodevelopment, and the Metaphysics of Agency}

We will assume with the tradition that a written contract is a promise that implies a commitment to satisfy the terms stated therein. In this section, we will use the framework offered in the previous sections to understand the importance and role of an agent's capacity to contract. We will also draw attention to a shortcoming of the understanding of the capacity to contract in Anglo-American jurisprudence. More specifically, we will shed some light on a shortcoming in the tradition with respect to who satisfies the capacity condition.

\footnotetext{
22 The following example is presented in Braucher and Farnsworth 1981, Section 15, "A, a school teacher, is a member of a retirement plan and has elected a lower monthly benefit in order to provide a benefit to her husband if she dies first. At age 60 she suffers a 'nervous breakdown,' takes a leave of absence, and is treated for cerebral arteriosclerosis. When the leave expires she applies for retirement, revokes her previous election, and elects a larger annuity with no death benefit. In view of her reduced life expectancy, the change is foolhardy, and there are no other circumstances to explain the change. She fully understands the plan, but by reason of mental illness is unable to make a decision based on the prospect of her dying before her husband. The officers of the plan have reason to know of her condition. Two months after the changed election she dies. The change of election is voidable."
} 
Suppose that we are right in how we characterized capacities in section 3 of this paper. If we are right, then a capacity is just a relatively non-specific, complex dispositional property of an object that is composed of more basic powers of an object. We have offered some reasons for taking this general account of capacities to provide the grounds for understanding the capacity to respond to reasons possessed by any rational agent (in the sense of "rational agent" outlined in section 3).

The capacity to contract will just be grounded in the reasons-responsive capacity of an agent that is directed at various manifestations depending upon the content of a contract. All other things being equal, the manifestations of an agent's capacity to contract just is the agent's responding in accordance with the reasons provided by a contract's varied terms. For instance, consider an agent, Joaquin, and his entering into a one-year contract with a record club. The terms of the contract state that Joaquin will select one of the LPs in the record club catalogue every month and send payment upon receipt of the LP. If he fails to select a record, he will be sent the featured LP of the month. In either case, he will owe the record club for the amount of the LP he is sent (whether or not he actively selected an LP or was automatically sent the record of the month).

Joaquin's failure to meet the contract's terms at any time may be due to a number of factors. For instance, the capacity to fulfill the terms of the contract may be lost or inhibited by being masked, or partially masked. In the case of losing the capacity, this may be temporary or permanent. In the case of masking and partial 
masking, Joaquin simply cannot manifest the capacity because of the manifestation of another power of his that blocks or impedes the manifestation of the capacity.

Consider the following example of temporarily losing a capacity. Joaquin may have failed to budget appropriately and he does not have the money necessary to pay for his monthly LP. He still has the capacity to contract, but he has lost the capacity to fulfill its terms. Nonetheless, he is penalized according to the terms of the contract.

The manifestation of other powers and capacities might mask Joaquin's capacity to fulfill the terms of the contract, not unlike how the manifestation of King Midas's power to turn things to gold by touching them masked his power to feed himself. ${ }^{23}$ Similarly, Joaquin's being busy doing other things (manifesting other powers) that result in his being distracted with other tasks masks his capacity to fulfill his contract, resulting in his failing to recognize and then appropriately manifest his capacity to fulfill the contract's terms.

We just mentioned the capacity to fulfill the terms of one's contract, but what about the capacity to contract? Suppose that Joaquin went to a pub where a representative for the record club had a promotional table. The record club is sponsoring a happy hour with half off all drinks. After eight servings of a mixture of assorted high alcohol Belgian ales drunk successively within less than two hours, Joaquin has reached the point where he is unquestionably inebriated. Given his drunken state, while he still possesses the capacity to contract, the capacity is masked by his drunkenness.

23 This example is borrowed from Molnar 2003, 93. 
Suppose Joaquin's friend, Aiko, is schizophrenic and believes the record club representative is a representative of the Dark Lord Cthulu who is offering her sanctuary from the wrath to come if she will only agree to buy one LP every month. In this case, Aiko lacks the requisite capacity altogether. She may have a compromised reasons-responsive capacity but it is not sufficient to ground the capacity to contract in her. So the capacity to contract is masked in Joaquin and missing in Aiko. In either case, the agents do not satisfy the terms of the capacity condition we find in Anglo-American contract law.

It is not altogether clear what to think about Joaquin's younger sister, Lydia. Lydia is not an adult but is on the verge of being legally an adult since she will turn 18 in less than one month.

Contrast Lydia with Aiko's younger brother, Shusaku, who is only ten years. Shusaku clearly lacks capacity. Assume that Shusaku has in place many of the powers necessary for him to have the capacity to contract. Given that his power to assess risk rationally and understand the nature of the promise he makes when entering a contract is not fully developed, the law seems to get things right when it states that he lacks the capacity to contract.

When we shift back to Lydia, we find that the law states that Lydia will have capacity to contract in less than one month. At 12:00 a.m. on the day of her birthday she goes from lacking capacity to suddenly having it. Anglo-American contract law seems to regard the change in a person's age from 17 to 18 to matter a great deal for whether or not one satisfies the capacity condition. But whether the law does a good job at tracking the truth of the matter is questionable. 
That a young adult like Lydia genuinely possesses the requisite capacity needed to ground the law's ascription of capacity to contract to her is questionable. The power of adolescents to control impulsive decision-making is not as developed as what we find in adults. In particular, there is a heightened tendency toward risktaking among adolescents compared to what we find among adults. This is not because they fail to perceive risk or their own vulnerability to risk (Cauffman and Shulman, et al., 2010, 193; Steinberg 2007). Rather, as Laurence Steinberg and others working in developmental neuroscience and developmental psychology have recognized, it seems it is due to competition between the regions that compose the cognitive-control network in an adolescent's brain and those that compose the socioemotional network (Steinberg 2008, 96; Cauffman and Shulman, et al. 2010; Ernst, et al. 2005).

The cognitive control network is mainly composed of outer cortical regions of the brain-e.g., the lateral prefrontal and parietal cortices along with the regions of the anterior cingulate cortex to which they are connected. It is active in executive control processes, such as planning and self-regulation. The socioemotional network is localized in the limbic system and paralimbic areas of the brain-e.g., the amygdala, ventral striatum, orbitofrontal cortex, medial prefrontal cortex, and superior temporal sulcus. It is sensitive to emotional and social stimuli and active in reward processing (Steinberg 2007, 56).

Risk-taking is "the product of a competition between the socioemotional and cognitive-control networks ..., and adolescence is a period in which the former abruptly becomes more assertive ... while the latter gains strength only gradually, 
over a longer period of time" (Steinberg 2007, 56). The high activation of the socioemotional network is not constant, but it is triggered when interacting with peers or during periods of heightened emotional arousal. The result is the suppression of the cognitive-control network (Ibid.). To use the ontological framework assumed in this paper, the powers of an agent that compose the cognitive-control network are inhibited by being masked (or at least partially masked) by the manifestation of some of the powers of the socioemotional network. The result is irrational decision-making.

A consequence of the foregoing is that risk taking and impulsive behavior motivated by a preference for smaller immediate rewards over larger delayed rewards is more common in adolescents owing to the high activation of the socioemotional network without a corresponding heightened activation of the cognitive-control network (McClure, et al. 2004; Ernst, et al. 2005). Peer-pressure is a particularly pronounced factor that contributes to risky decision-making. In one of Steinberg's studies, peer pressure doubled the number of risks teenagers took in a video driving game and, importantly for our purposes in this paper, "increased risk taking by $50 \%$ among college undergraduates" (which is around 18-22 in most common law countries) (Steinberg 2007, 57; Gardner and Steinberg 2005).

What is important for our purposes is that the powers that moderate risktaking, such as impulse control, emotion regulation, and delay of gratification, continue to develop into young adulthood (Steinberg 2007, 56). The upshot is that not only is an adolescent's capacity to properly respond to reasons and avoid risky behavior not as developed as what we find in an adult with a more mature and 
developed socioemotional network and cognitive-control network, but among younger adults there is a similar lack of a fully developed capacity to avoid risky behavior.

One may wonder what the foregoing has to do with someone like Lydia. She will be an adult soon. But the change in her legal status does not effect a change in her neurodevelopment. On the day she turns 18 , we can safely assume that she, like other young adults, will be prone to making risky decisions. Returning to the powers that compose the capacity to respond to reasons that grounds the capacity to contract, it is reasonable to regard her as not in full possession of the relevant powers. We cannot truthfully say with any confidence that she is in full possession of the capacity to contract.

One may wonder why we would say that we cannot truthfully describe Lydia as being in full possession of the capacity to contract. The reason is because we have good reason to believe that Lydia's socioemotional network is not fully developed. Hence, she is more vulnerable to influences that would mask or partially mask her capacity to respond to reasons. Her vulnerability would be manifested in her being more likely to take risks when subjected to peer pressure or other influences that would serve as manifestation partners with her vulnerability. The manifestation of her vulnerability would mask her capacity to respond to reasons if she is unable to manifest any of the powers that compose her capacity. Her capacity to respond to reasons would be only partially masked if, for instance, she has difficulty manifesting her capacity because her power to appreciate any of the risks, burdens, and responsibilities that she would take on as a result of entering into a contract 
would be unable to be simultaneously manifested because of the manifestation of her vulnerability. The power in question would be among those that compose her capacity to respond to reasons that grounds her capacity to contract and its being masked would impede/partially mask her capacity to contract, making it difficult for her to effectively respond to any considerations there may be for her not to enter into a contract.

Suppose it is Lydia's $18^{\text {th }}$ birthday. She is considering joining the record club of which Joaquin is a member. Now that she is 18 , she can join the club. Her friends are all members and she finds herself with a strong impulse to join whenever she comes across advertisements for the record club on the television, on the web, and in the magazines she reads. The advertisements are targeting young adults and appeal to the desire of many to be hip. The manipulative influence of the advertising and the influence of her peers serve as manifestation partners with her vulnerability to risky and impulsive decision-making, the outcome of their interaction is a strong (almost overwhelming) urge to join the record club that ultimately results in her agreeing to join when presented with the contract. The powers that compose her cognitive control network that are at least partially constitutive of her capacity to respond to reasons that grounds her capacity to contract are partially masked and, hence, the network is suppressed. The result is that she discounts any potential long-term costs in favor of the short-term gains that joining the record club afford her.

If we are right about the foregoing, then since an adolescent who is 17 and one day away from turning 18 is truthfully described as lacking the capacity to contract 
by the law, we should take Lydia, who just turned 18 to similarly lack the capacity. The legal standard notwithstanding, we have no reason to believe that the small difference in age makes any difference with respect to their respective capacities. And this difference suggests that Anglo-American contract law fails to track the lack of any real difference between these agents. Hence, some modifications in the law are necessary.

\section{Some Potential Solutions to Consider}

Contract law in Anglo-American jurisprudence assumes that entering adulthood results in an agent's being in possession of the capacity to contract. But, as we have shown above, things are not so neat and tidy as the law presumes. Precisely what course of action should be taken to remedy this situation is not clear. We do not want to strip young adults of their autonomy, but if they do not clearly satisfy the capacity condition, then it would seem that some policy changes are in order.

We have no settled views on what the best change in policy (if any) might be. We will here consider three options that strike us as reasonable: (i) limit the types of contracts young adults may enter; (ii) afford judges discretion in ascertaining capacity in cases of disputed contracts; and (iii) combining (i) and (ii) into a hybrid solution. Each option has problems. Also, we do not wish to suggest that these exhaust the available alternatives. But they are representative of some broad strategies that may be worthy of consideration.

\subsection{Option 1: Limited contracts}

The first option is one that reflects current practices in the United States with respect to the rights of young adults. In the United States, the age of majority is 18 in 
most states and territories. Young adults who have just turned 18 may vote, acquire driver's licenses without obtaining the signature of a parent or guardian, purchase cigarettes, enlist in the military, and do many other things that their peers who are under 18 cannot do. However, in the United States, the purchase and consumption of alcohol is prohibited until age 21 . While the reasons for this may not have been motivated by the best reasons, and the effectiveness of this policy are questionable, what is relevant for our purposes is that, at least in one common law jurisdiction, that the legal rights and privileges of young adults do not come in an all-or-nothing bundle is not without precedent.

There are two possible ways of developing this sort of policy. On one approach, we raise the age of when an agent has the capacity to contract from 18 to 21. This, however, seems like too strong of a proposal. Just as the effectiveness of the "all or nothing" approach to the right to drink alcohol in making young adults into responsible consumers of alcohol is questionable, a similar approach in contract law may not enable young adults to gradually learn how to be rational decision-makers when entering into contracts.

A perhaps more modest proposal would be to permit 18 year olds to enter into some types of contracts (e.g., lease agreements for housing, automobile loans, education loans, and, yes, even record clubs) while not allowing them to sign other types of contracts without either obtaining legal counsel or the approval of a parent 
or legal guardian who will assume the risks and responsibilities stated in the contract until the young adult turns 21 (e.g., mortgages, business loans, etc.). ${ }^{24}$

Of course, some may object that any such policy change amounts to unjustifiable legal paternalism. Our interlocutor may invoke J.S. Mill’s Harm Principle, arguing that any curbs on our legal freedom to contract should only be introduced to avoid causing harm to others (Mill 1859/1912,15). The question now, however, is who stands to be harmed by a contract? It seems to us that it is young adults who are the signees to a contract who stand to be harmed. Hence, the restriction should be seen more as a restriction on the freedom of those who would promote and attempt to influence young adults to enter into contracts that may harm them. This is paternalistic. But if we understand the primary restriction as being imposed on those who would promote and attempt to get young adults to enter contracts with them, then we can see that the restriction, while paternalistic, is not aimed at restricting the freedoms of young adults but is aimed at reducing the likelihood of certain harms to young adults.

\subsection{Option 2: Affording judges discretion in ascertaining capacity}

We may wish to leave the range of types of contracts young adults may enter unchanged. If so, an alternative policy would be to continue to presume that those who are 18 or older have the capacity to contract. But we may afford judges more

\footnotetext{
${ }^{24}$ It may be that some reform with respect to the regulation of the promotion of some products would be required for any such changes to be effective.
} 
discretion in court cases where the signee claims that they fail to satisfy the conditions stipulated for having the capacity to contract.

Effectively implementing this change would require that justices become familiar with the relevant developmental neuroscience. The Macarthur Foundation has already spearheaded this sort of initiative in the United States. One result was the publication of $A$ Judge's Guide to Neuroscience: A Concise Introduction (Gazzaniga, et al., 2010). The Guide, however, focuses on criminal law. Either a guide for contract law would be needed or else the current guide would need to be updated to include a section on legal capacity and contract law.

Other steps would need to be taken to ensure that justices are well equipped to make informed rulings in such cases. Additionally, more guidelines need to be in place for determining capacity in young adults. These may be similar to those in place for assessing whether an agent's mental disability inhibits their capacity to contract and excuses them from satisfying the terms of a contract. The alternative two-pronged incapacity defense discussed above under section 4 is an example of the kind of standard that could be used by judges when a person raises minority as a defense. This would require legislative action, not like in the case of the first option.

Of course, effectively implementing this sort of policy change would not be easy. As noted, the biggest challenge, of course, is ensuring that all of the justices who may hear cases where there is a contractual dispute have the requisite understanding of the relevant scientific data. They also need a clear conception of what capacities are and how the relevant capacities may be inhibited or masked. Finally, they must be able to apply this information to making informed decisions in 
cases where the legal capacity of an agent to contract is in question. Achieving this goal is a daunting task.

Notwithstanding the challenges posed by such a policy change, an advantage to it is that it may be less paternalistic than option 1 . Reliance on experts in any legal proceedings would relieve some of the burden on justices. But that justices understand data with which they are presented must be stressed. Hence, at least some education of justices would be required. This would be a huge project in some jurisdictions (like in the United States). Hence, it may not be the most efficient option.

Finally, unlike option 1, option 2 may result in a chilling effect when it comes to the willingness of lenders and others to enter into contracts with young adults. While option 1 would simply bar young adults from entering into certain contracts, option 2 does not restrict their options. But lenders and others who may provide services that involve contracts may be less willing to do business with young adults under option 2.

\subsection{Option 3: The hybrid approach}

It may be suggested that a synthesis of the first two options may be the most promising approach. Of course, while such an approach may allow us to fuse together the strengths of each of the other two options, this approach may still inherit the liabilities of the other two approaches. Also, depending upon how we

implement increased judicial discretion along with restrictions on the types of contracts young adults may enter, it is hard to see how it differs from the first option. 
We should explain this last point. If the first option were implemented, there would still be disputes over whether a given contract is a token of a type that young adults are barred from signing. Hence, some judicial discretion would have to be exercised in cases where things are not so clear. Thus, some increased judicial discretion in these matters is inevitable once we introduce policies that are like the first option. The result is that option 1 already implies something like option 3. Moreover, it does so in a way that is much clearer. Specifically, judicial discretion on this model can now be exercised in cases where there is some vagueness that needs to be resolved. But the extent of judicial discretion is not as far reaching as what we have with option 2 . Whether this means that option 1 is the best option or not is not something we are prepared to commit to at this juncture. For the purposes of this essay, what matters is that there are some possible remedies worth exploring to close the gap that exists in contract law that makes it possible for persons whose capacity to contract (or at least whose capacity to enter into certain types of contracts given various factors) is questionable.

\section{Conclusion}

In this paper, our goal was to provide an ontological framework that could ground a metaphysics of intentional agency that might prove useful for thinking about the capacity to contract. In particular, we were aiming at providing a framework that would help us think about hard cases like the one we focused on in this paper involving young adults. If we are right, a result of our project is that we have exposed a significant lacuna in contract law. While we have exposed a gap, we think that some empirical work needs to be done to determine how problematic this gap 
has actually been in practice. From there, we need to consider what should be done, if anything. The options sketched are just some suggested fixes. In any case, assuming the present standard is inadequate and some policy changes are needed, we would encourage any moves that would lead to pursuing and implementing positive changes in Anglo-American contract law.

\section{References:}

Aguilar, J. and Buckareff, A. (2010) Causing human actions: new perspectives on the causal theory of action. Cambridge, MA: The MIT Press.

Armstrong, D. (1978) A theory of universals. New York: Cambridge University Press.

Armstrong, D. (1989) Universals: an opinionated introduction. Boulder: Westview Press.

Armstrong, D. (1997) A world of states of affairs. New York: Cambridge University Press.

Braucher, R. and Farnsworth, E. (eds.) (1981) Restatement of the law, second, contracts. Philadelphia: American Law Institute.

Campbell, K. (1981) The metaphysic of abstract particulars. Midwest Studies in Philosophy, 6, 477-88.

Campbell, K (1990) Abstract particulars. Malden, MA: Basil Blackwell.

Cauffman, E. and Shulman, E., Steinberg, L., Claus, E. and Banich, M., Graham, S., and Woolard, J. (2010) Age differences in affective decision-making as indexed by performance on the Iowa gambling task. Developmental Psychology, 46, 193207. 
Dancy, J. (2000) Practical reality. New York: Oxford University Press.

Davidson, D. (1980) Causal relations. In Essays on actions and events (pp. 149-162). New York: Oxford University Press.

Engelhard, K. (2010) Categories and the ontology of powers: a vindication of the identity theory of properties. In A. Marmodoro (ed.) The metaphysics of powers: their grounding and their manifestations (pp. 41-57). New York: Routledge.

Ernst, M., Nelson, E., Jazbec, S., McClure, E., Monk, C., Leibenluft, E., Blair, J., and Pine, D. (2005) Amygdala and nucleus accumbens in responses to receipt and omission of gains in adults and adolescents. NeuroImage, 25, 1279-1291.

Fischer, J. (1995) The metaphysics of free will. Oxford: Blackwell.

Fischer, J. and Ravizza, M. (1998) Responsibility and control: a theory of moral responsibility. New York: Cambridge University Press.

Frankfurt, H. (1978) The problem of action. American Philosophical Quarterly, 15, 157-162.

Gardner, M. and Steinberg, L. (2005) Peer influence on risk taking, risk preference, and risky decision making in adolescence and adulthood: an experimental study. Developmental Psychology, 41, 625-635.

Garner, B. (ed.) (1999) Black's law dictionary, $7^{\text {th }}$ ed. St. Paul, MN: West Group. Gazzaniga, M., et al. (2010) A judge's guide to neuroscience: a concise introduction. Santa Barbara, CA: University of California-Santa Barbara. Heil, J. (2003) From an ontological point of view. New York: Oxford University Press. Heil, J. (2012) The universe as we find it. New York: Oxford University Press. 
Ingthorsson, R. (2013) Properties: qualities, powers, or both? Dialectica, 67, 55-80.

Jacobs, J. (2011) Powerful qualities, not pure powers. The Monist, 94, 81-102.

Martin, C.B. (2008) The Mind in Nature. New York: Oxford University Press.

McClure, S., Laibson, D., Loewenstein, G., and Cohen, J. (2004) Separate neural systems value immediate and delayed monetary rewards. Science, 306, 503507.

Mele, A. (2003) Motivation and agency. New York: Oxford University Press.

Mill, J. (1859/1912) On liberty. In J.S. Mill, Three essays. New York: Oxford University Press.

Molnar, G. (2003) Powers: a study in metaphysics. New York: Oxford University Press.

Mumford, S. (1998) Dispositions. New York: Oxford University Press.

Pratt, M. (2007) Promises, contracts, and voluntary obligations. Law and Philosophy, 26, 531-574.

Nelkin, D. (2011) Making sense of freedom and responsibility. New York: Oxford University Press.

Simester, A. (1996) Agency. Law and Philosophy, 15, 159-181.

Smith, M. (1994) The moral problem. Oxford: Blackwell.

Steinberg, L. (2007) Risk taking in adolescence: new perspectives from brain and behavioral science. Current Directions in Psychological Science, 16, 55-59.

Steinberg, L. (2008) A social neuroscience perspective on adolescent risk-taking. Developmental Review, 28, 78-106. 
Strawson, G. (2008) The identity of the categorical and the dispositional. Analysis, 68, 271-282.

Strawson, P. (1962) Freedom and resentment. Proceedings of the British Academy, $48,1-25$.

Williams, D.C. (1953) On the elements of being. The Review of Metaphysics, 7, 3-18, $171-92$.

Wolf, S. (1993) Freedom within reason. New York: Oxford University Press. 